\title{
PENERAPAN ELECTRONIC SUPPLY CHAIN MANAGEMENT DALAM UPAYA MENGATASI PENGADAAN BAHAN BAKU UNTUK PRODUKSI PADA PT. BANDAR WIREPRIMA
}

\author{
Erwin Saputra ${ }^{1)}$, Bullion Dragon Andah ${ }^{2)}$ \\ ${ }^{1}$ Sistem Informasi, Fakultas Teknologi Informasi, Universitas Budi Luhur \\ ${ }^{1,2} \mathrm{Jl}$. Raya Ciledug, Petukangan Utara, Kebayoran Lama, Jakarta Selatan 12260 \\ E-mail : 1412520015@student.budiluhur.ac.id ${ }^{1}$, bullion.dragon@budiluhur.ac.id $\left.{ }^{2}\right)$
}

\begin{abstract}
Abstrak
Semakin majunya perkembangan industri apapun, apabila tidak memiliki sebuah sistem yang tidak dapat memberikan informasi secara efektif dan efesien, akan berdampak buruk pada kelangsungan kehidupan perusahaan tersebut yang mengakibatkan sulitnya bersaing dengan perusahaan yang sudah menciptakan sistem informasi yang baik. Untuk meningkatkan hasil usaha, dibutuhkan sistem yang dapat menyampaikan informasi dari supplier sampai ke perusahaan secara efektif dan efesien. PT. Bandar Wireprima merupakan salah satu Perusahaan yang bergerak di bidang Industri Baja, salah satu jenis produksi dari PT. Bandar Wireprima adalah berupa Kawat Duri / Kawat Seng. Saat ini, proses pengadaan bahan baku terkadang mengalami keterlambatan dikarenakan respon yang lambat dari supplier, kualitas bahan baku yang tidak menentu dari supplier, sulitnya memprediksi stok bahan baku, dan tidak tersedianya informasi laporan harga yang pimpinan untuk pengambilan keputusan. Peneliti bertujuan untuk mengembangkan sistem yang sudah berjalan dengan pengumpulan data sebelumnya dan melakukan pendekatan melalui metode supply chain management. Penelitian ini dapat memberikan informasi berupa notifikasi pengingat untuk email ke supplier, membuat daftar laporan follow up supplier, laporan kebutuhan stock berupa grafik dan tabel, laporan rekapitulasi penawaran harga dan juga informasi daftar pencekalan supplier-supplier bahan yang kurang baik sehingga sistem Electronic Supply Chain Management ini dapat memberikan informasi yang dibutuhkan oleh perusahaan.
\end{abstract}

Kata kunci: Electronic Supply Chain Management, Pengadaan Bahan Baku, E-SCM.

\section{PENDAHULUAN}

Persaingan Bisnis antar perusahaan yang terjadi saat ini semakin hari, sudah semakin terlihat sangat jelas bagaimana mereka berlomba untuk lebih baik dari hasil yang akan dicapainya seiring dengan perkembangan teknologi informasi yang telah mengubah sistem perusahaan menjadi lebih mengutamakan strategi bisnis yang harus semakin baik, bukan hanya dalam proses pemasarannya saja, namun juga dalam proses pra-produksi dan produksi. Apabila diperhatikan, inti dari persaingan bisnis tersebut menjurus pada bagaimana sebuah perusahaan mampu menerapkan proses penciptaan suatu produk atau jasa menjadi lebih murah dan lebih berefisiensi dalam segala aspek. Pada proses penciptaan suatu produk, perusahaan dituntut untuk dapat lebih memperhatikan kinerja suatu perusahaan agar dapat bertahan dalam ketatnya persaingan bisnis yang terjadi [1]. Dengan hadirnya Supply Chain Management dapat membantu sistem informasi yang ada semakin baik, efektif dan efesien Mengidentifikasi proses bisnis serta menganalisa permasalahan yang berkaitan dengan proses pengadaan bahan baku, proses produksi, pengecekan stok bahan baku, dan penambahan sistem pengaturan penyimpanan bahan baku di gudang bahan baku hingga pencatatan supplier yang dinilai kurang baik dalam segi kualitas bahannya sehingga dikemudian hari, pihak Perusahaan dapat mensortir supplier yang akan di pilih untuk pembelian bahan produksi [2]. PT. Bandar Wireprima merupakan salah satu perusahaan yang bergerak di bidang industri baja dengan salah satu produk yang dihasilkan ialah Kawat duri, kawat seng, dan berbagai jenis kawat lainnya yang bertempat di daerah Tangerang PT. Bandar Wireprima memiliki beberapa kendala dalam proses bisnis perusahaan diantaranya adalah Kurangnya Koordinasi dengan supplier dalam pengadaan bahan, tidak ada informasi kebutuhan stock bahan yang akan digunakan, keterbatasan informasi harga bahan baku, dan tidak tersedianya informasi supplier-supplier bahan yang kurang baik untuk diproduksi. penulis mencoba menganalisa dan memberikan solusi agar dapat membantu mengatasi kendala yang dialami oleh PT. Bandar Wireprima. Guna meningkatkan target produksi yang memiliki kualitas baik dan akurasi waktu yang tepat dlam produksi barang [3]. Informasi merupakan data yang sudah diolah yang ditujukan untuk seseorang , orgnasisasi ataupun siapa saja yang membutuhkan. Informasi akan menjadi berguna apabila objek yang menerima informasi membutuhkan informasi tersebut [4]. 


\section{METODE PENELITIAN}

Penelitian yang dilakukan penulis mulai dari pengumpulan data, pengidentifikasian masalah, hingga diimplementasikan ke dalam perancangan sebuah sistem.

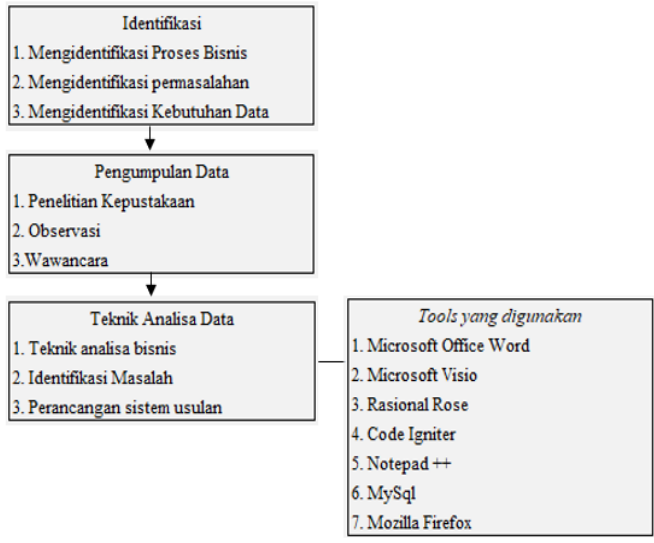

Gambar 1. Tahapan penelitian

Gambar 1 dapat diuraikan suatu metode yang digunakan dalam tahapan penelitian yang digunakan oleh penulis yaitu :

1. Identifikasi masalah yakni dengan cara mengidentifikasi permasalahan yang terjadi pada perusahaan dengan cara menganalisa suatu proses bisnis yang berjalan serta melihat kebutuhan data dari perusahaan.

2. Pengumpulan data yaitu dengan mencari informasi melalui wawancara langsung pada bagian terkait permasalahan di perusahaan, survey langsung ke tempat riset dimana bagian yang mengalami permasalahan, menganalisa dokumen-dokumen berjalan dan mengumpulkan data-data dari perpustakaan sesuai kebutuhan yang terkait.

3. Teknik analisa data yaitu dengan menganalisa sistem berjalan perusahaan tersebut ke dalam bentuk activity diagram, memahami masalah yang terjadi dan dituangkan ke dalam model fishbone guna mempermudah Analisa permasalahan dan merancangkan sistem usulan dengan mengikuti sistem yang sudah berjalan dan memberikan tambahan informasi terkait masalah yang ada untuk solusi pada masalah tersebut.

4. Tools yang digunakan dalam perancangan sistem adalah Office Word yang membantu proses pengetikan, Visio yang membantu dalam pembuatan activity diagram \& fishbone, ERD, LRS, Rasional Rose yang digunakan untuk pembuatan sequence diagram, code igniter dan notepad ++ digunakan untuk membantu mengaplikasikan sistem prototype yang dibuat, Mysql digunakan untuk pembuatan database, dan Mozilla firefox digunakan untuk menjalankan program.

\section{HASIL DAN PEMBAHASAN}

PT. Bandar Wireprima adalah perusahaan swasta yang betempat Jl. Raya Kalibaru, Kawasan Industri 19 Sungai Yuri Blok B1 No.3 TangerangIndonesia. PT. Bandar Wireprima berdiri sejak tahun 2008 dan produksi yang dihasilkan di bidang kawat duri beberapa produk lainnya seperti Kawat Seng/Kawat Galvanize, Kawat Beton/Bendrat, Kawat Duri, Rantai Galvanis, Wire Hanger.

Pada gambar 2 sampai 7 Sistem berjalan pada PT. Bandar Wireprima :

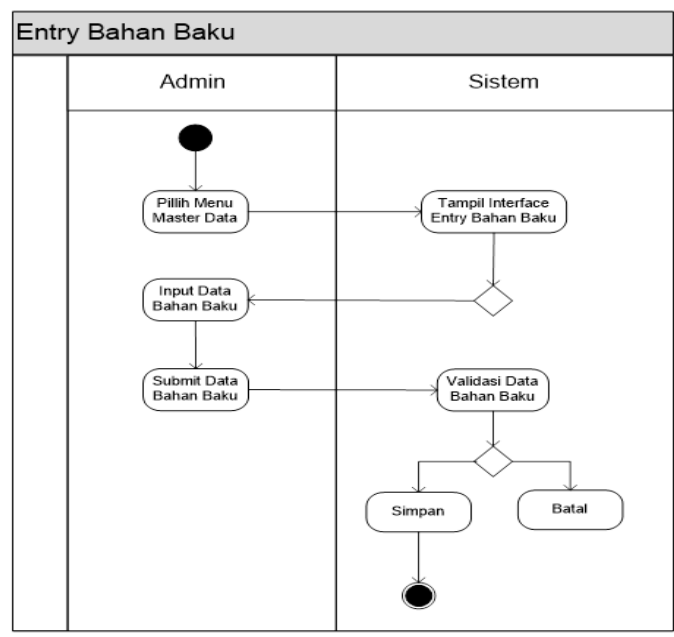

Gambar 2. Entry data Bahan Baku

Gambar 2 menjelaskan mengenai alur proses entry data master bahan baku yang dapat diakses oleh staff purchasing.

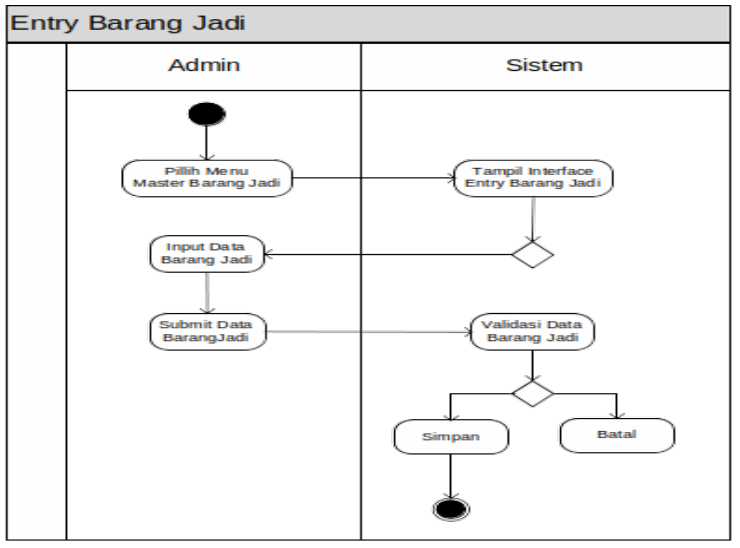

Gambar 3. Entry data master Barang Jadi

Gambar 3 merupakan proses entry data barang jadi yang dapat diakses oleh Staff Purchasing. 


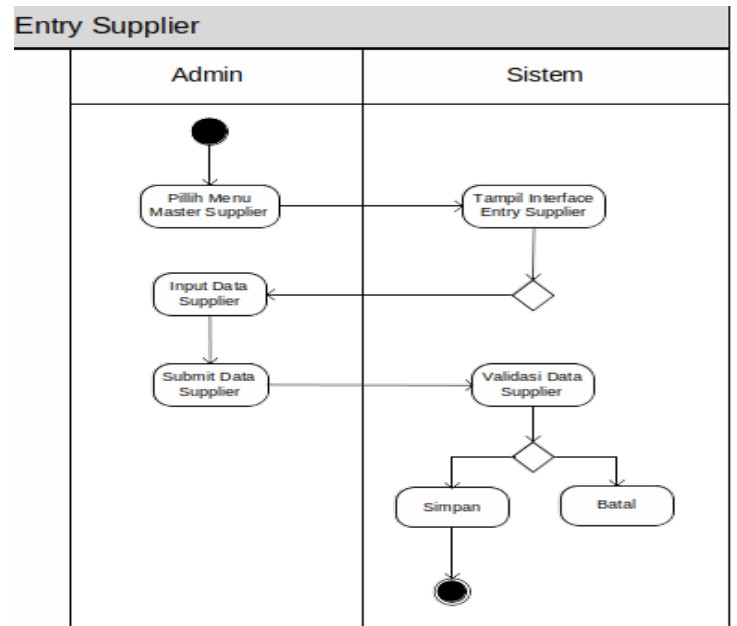

Gambar 4. Entry data master Supplier

Gambar 4 merupakan penjelasan suatu proses entry Supplier yang dapat diakses oleh Staff Purchasing.

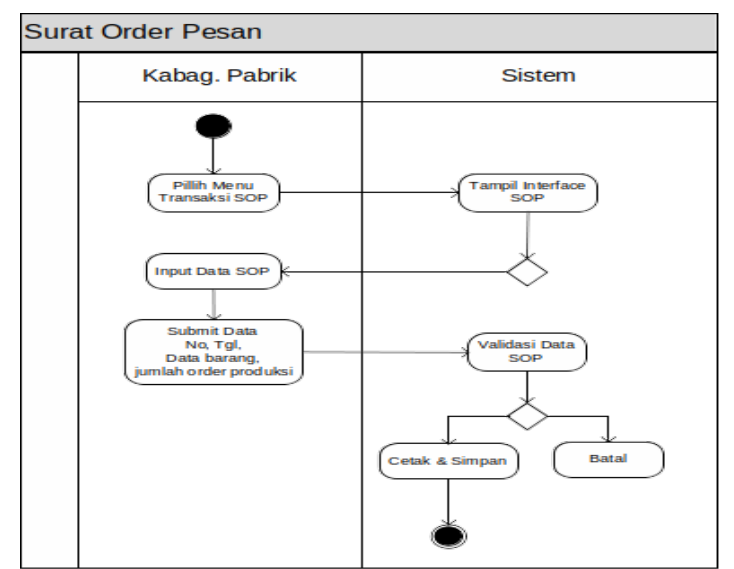

Gambar 5. Surat Order Produksi

Gambar 5 merupakan proses entry Surat Order Produksi yang dapat diakses oleh Kabag Pabrik / Staff Produksi.

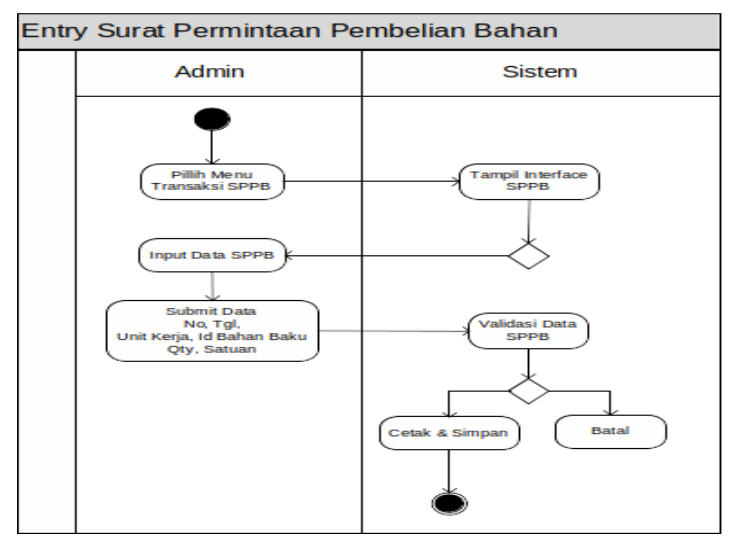

Gambar 6. Surat Permintaan Pembelian Bahan
Gambar 6 merupakan proses Surat Permintaan pembelian bahan yang dapat diakses oleh Staff Purchasing.

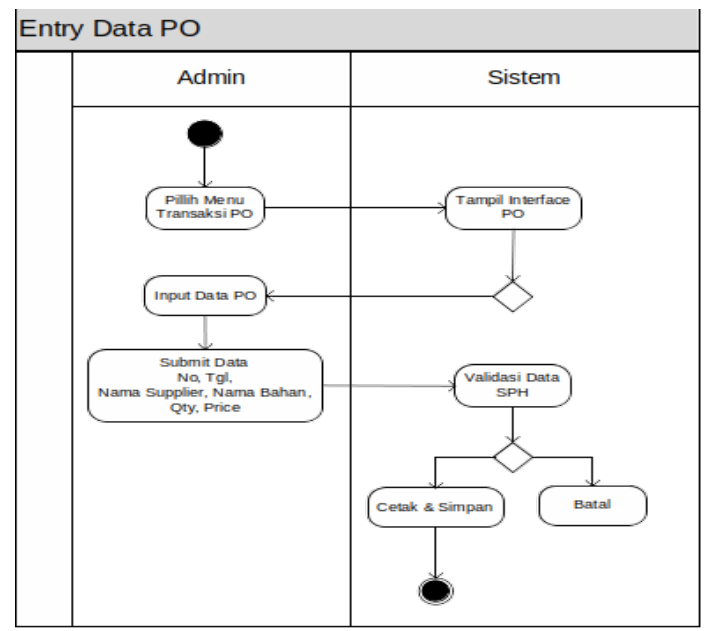

Gambar 7. Data PO

Gambar 7 adalah proses cetak data PO yang dapat diakses oleh staff purchasing.

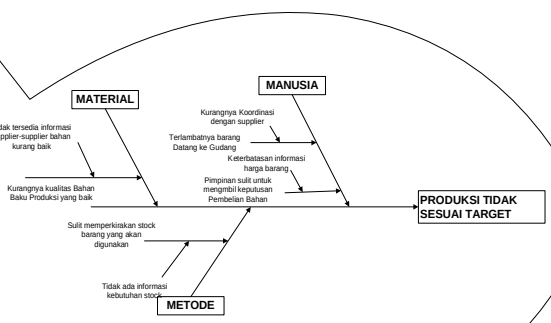

Gambar 8. Fishbone Analisa Masalah

Gambar 8 menerangkan diagram fishbone analisa masalah yang dialami oleh PT. Bandar Wireprima.

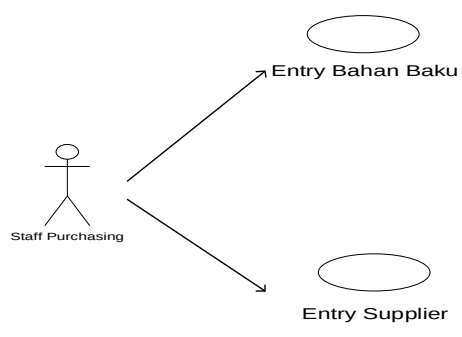

Gambar 9 merupakan penjelasan tentang use case data master yang akan di buat untuk rancangan usulan. 


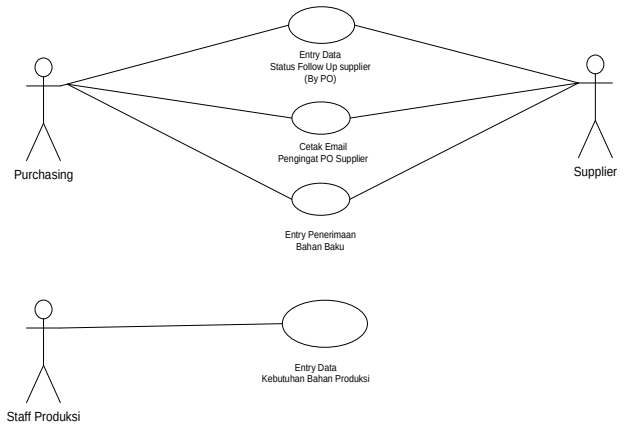

Gambar 10. Use case Transaksi

Gambar 10 adalah use case transaksi yang akan di buat untuk rancangan usulan.

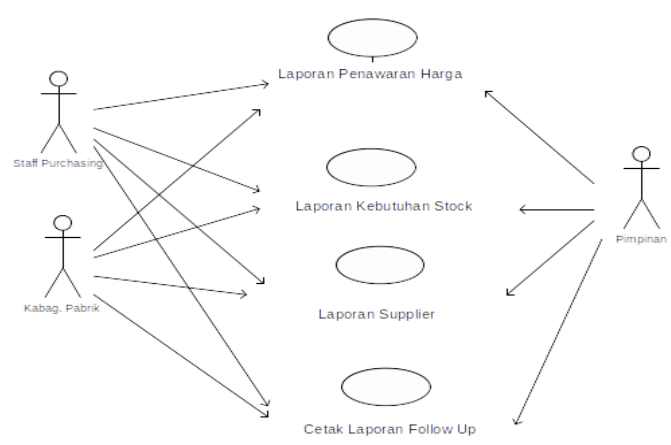

Gambar 11. Use Case Laporan

Gambar 11 merupakan use case laporan yang akan di buat untuk rancangan usulan informasi berupa laporan.

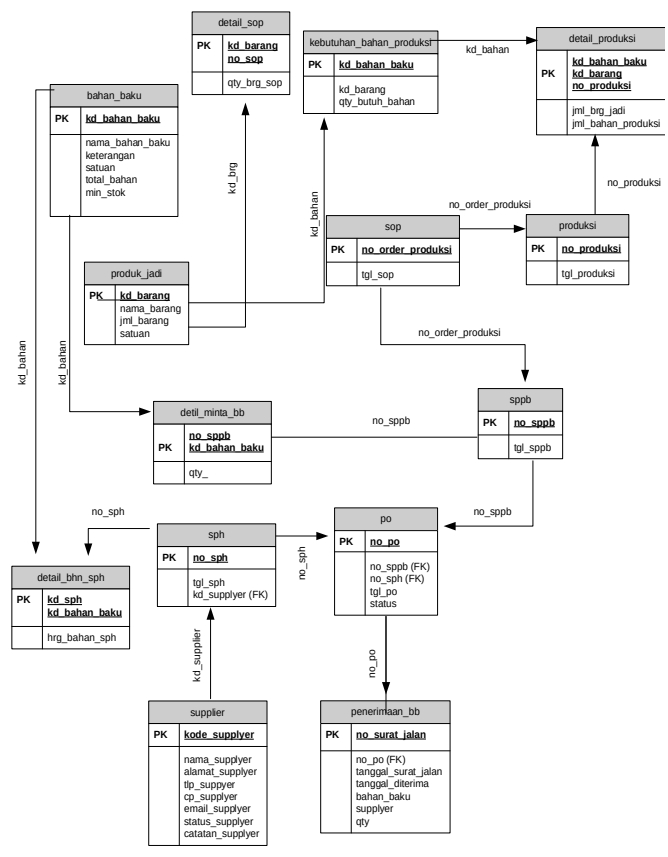

Gambar 12. Logical Record Structure
Gambar 12 menjelaskan Logical Record Structure yang dibuat untuk tabel database.

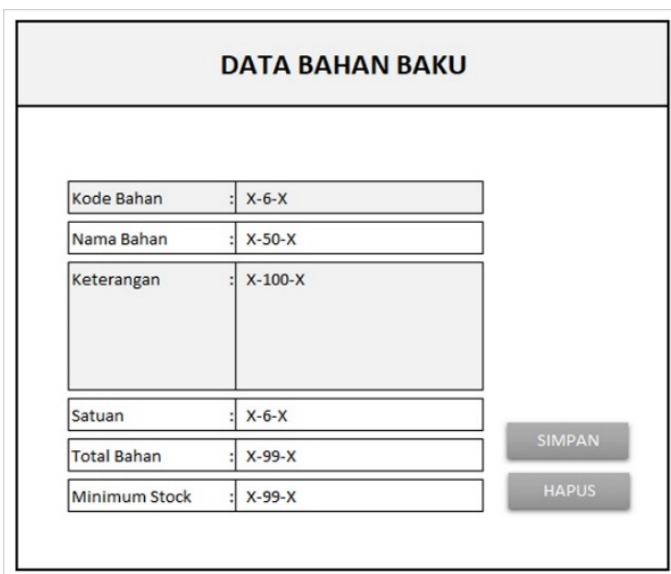

Gambar 13. Rancangan Layar Entry Bahan Baku

Gambar 13 merupakan rancangan layar untuk entry bahan baku dan penambahan field minimum stok

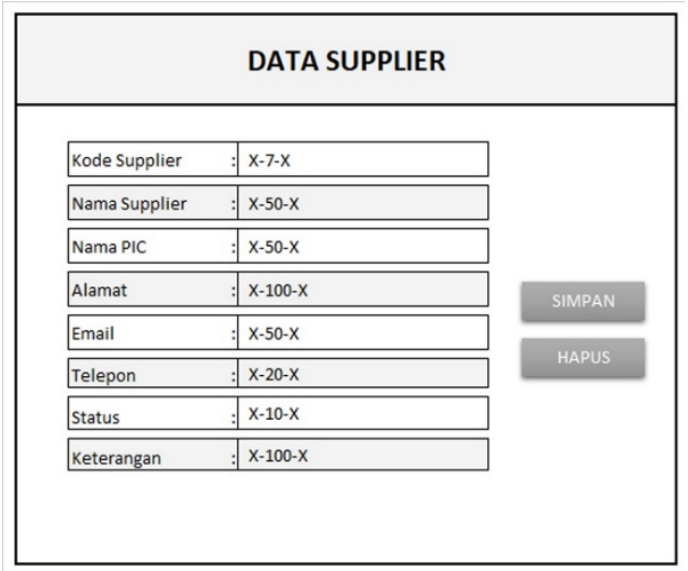

Gambar 14. Rancangan Layar Entry Supplier

Gambar 14 adalah suatu rancangan layar untuk entry Supplier dan akan menampilkan status supplier blacklist atau status OK.

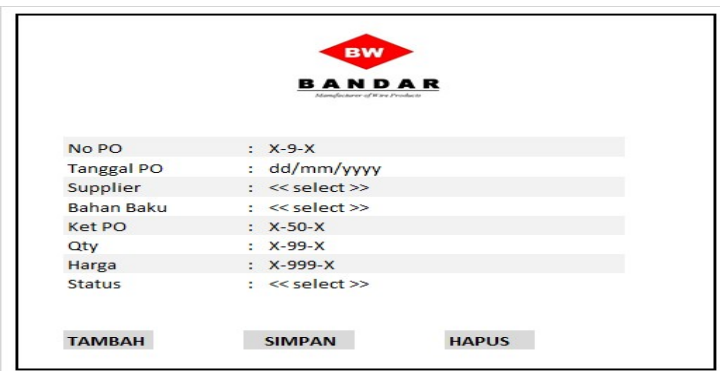

Gambar 15. Rancangan Layar Data Status Follow Up (By PO)

Gambar 15 merupakan rancangan layar untuk status follow up PO ke customer yang nantinya akan 
terdapat notifikasi pengingat kepada purchasing untuk follow up ke supplier.

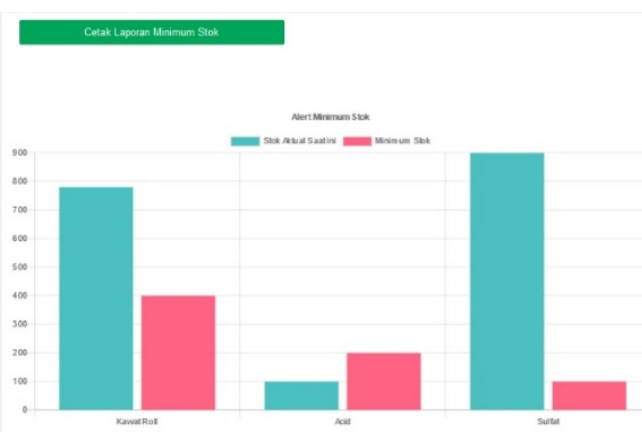

Gambar 16. Rancangan Layar Laporan Minimum Stock

Gambar 16 merupakan rancangan layar untuk laporan minimum stock berupa tabel dan grafik.

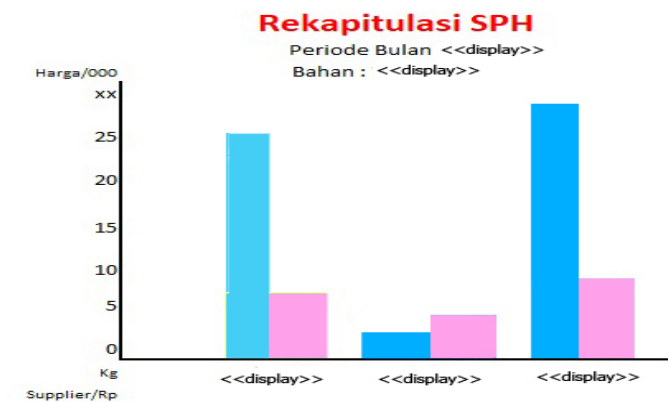

Gambar 17. Rancangan Layar Laporan Rekapitulasi Penawaran Harga

Gambar 17 menjelaskan rancangan layar untuk laporan rekapitulasi penawaran harga untuk mendapatkan pimpinan dengan mudah mengambil keputusan pembelian bahan baku yang relatif murah.

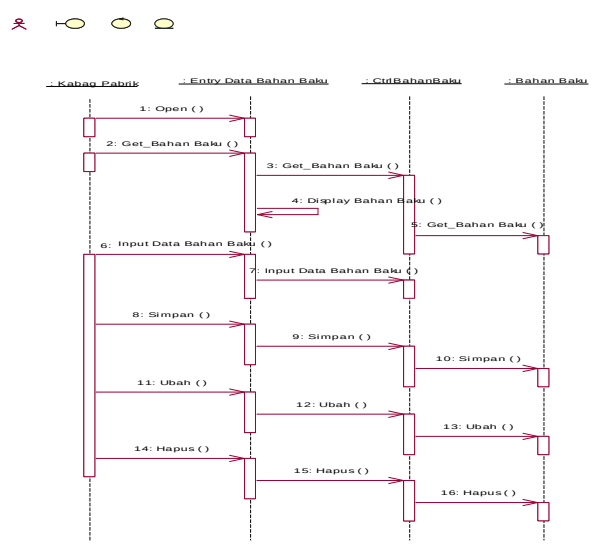

Gambar 18. Sequence Diagram Entry Bahan Baku

Pada Gambar 18 di atas menjelaskan tentang sequence diagram entry bahan baku berdasarkan rancangan sistem yang diusulkan.
Tabel 1. Tabel Analisa Masalah

\begin{tabular}{|c|c|}
\hline $\begin{array}{l}\text { Kurangnya Koordinasi } \\
\text { dengan supplier }\end{array}$ & $\begin{array}{ll}\text { a. } & \text { Membuat } \\
& \text { Notifikasi } \\
& \text { Pengingat Untuk } \\
\text { email ke supplier } \\
\text { b. } \\
\text { infombuat } \\
\text { laporan follow up } \\
\text { supplier }\end{array}$ \\
\hline $\begin{array}{l}\text { Tidak ada informasi } \\
\text { kebutuhan stock }\end{array}$ & $\begin{array}{l}\text { Laporan kebutuhan stock } \\
\text { (berupa Grafik dan Tabel } \\
\text { Kebutuhan Stock) }\end{array}$ \\
\hline $\begin{array}{l}\text { Keterbatasan informasi } \\
\text { harga bahan baku. }\end{array}$ & $\begin{array}{l}\text { Membuat } \quad \text { Laporan } \\
\text { Rekap-itulasi } \\
\text { harga }\end{array}$ \\
\hline $\begin{array}{l}\text { Tidak tersedia infor- } \\
\text { masi supplier-supplier } \\
\text { bahan kurang baik. }\end{array}$ & $\begin{array}{lr}\text { Membuat } & \text { List } \\
\text { Pencekalan } & \text { supplier } \\
\text { bahan yang kurang baik. }\end{array}$ \\
\hline
\end{tabular}

\section{KESIMPULAN}

Setelah mempelajari masalah yang di hadapi dan solusi pemecahan yang diusulkan, maka dapat ditarik kesimpulan sebagai Berikut:

1. Masalah kurangnya koordinasi dengan supplier dikarenakan follow up yang terlewat sehingga bahan baku lama di kirim dapat dikurangi dengan adanya notifikasi follow up berupa email notifikasi ke supplier yang berfungsi notifikasi pengingat untuk supplier dan notifikasi pengingat untuk purchasing

2. Masalah tidak adanya informasi kebutuhan stock dapat dikurangi dengan adanya penambahan field pada master data bahan baku yaitu minimum stock dan pembuatan laporan stock bahan baku, sehingga notifikasi akan muncul pada saat bahan baku menyentuh angka minimum stock.

3. Masalah keterbatasan informasi harga bahan baku yang berdampak pada keputusan pemimpin untk memilih harga bahan baku yang termurah bahkan termahal, dapat dikurangi dengan adanya laporan rekapitulasi penawaran harga bahan baku untuk lebih spesifikasi melihat nilai terendah dari suatu bahan baku yang akan di pesan.

4. Masalah tidak tersedianya informasi supplier-supplier bahan kurang baik, yang berdampak pada kualitas dan kuantiti produk yang akan diproduksi dapat 
dikurangi dengan adanya list pencekalan supplier-supplier bahan kurang baik, sehingga purchasing dan pimpinan dapat melihat rekap supplier bahan mana yang baik dan kurang baik untuk dipilih menjadi supplier bahan yang akan di pesan

Agar sistem usulan ini dapat berjalan dengan baik sesuai harapan, maka penulis mempunyai saran yang bermanfaat bagi perkembangan dan implementasi sistem usulan ini sebagai berikut:

1. Diperlukan analisa dan pemeliharaan sistem secara berkala sehingga sistem yang berjalan dapat membantu segala kebutuhan tanpa ada kendala.

2. Melakukan Maintenance hadware secara rutin untuk kesetabilan penggunaan sistem.

3. Perlu dilakukan backup secara berkala untuk menghindari hilangnya data-data saat terjadi kerusakan sistem

4. Penulis menyadari sistem ini masih belum sempurna, mungkin dari pihak perusahaan ataupun dari pihak peneliti selanjutnya dapat mengupgrade sistem supply chain management ini menjadi lebih baik lagi dan lebih terefesiensi dengan baik.

\section{DAFTAR PUSTAKA}

[1] Prihatmanto, B, Supply Chain. Jakarta: Kompas Gramedia, 2018.

[2] Sakti, F. (2016). Konsep Supply Chain Management (SCM) Pda proses produksi dalam Pengeleloaan Persediaan Bahan Baku. Jurnal Teknologi Informasi, Volume 12, Nomor 2, Agustus 2016.

[3] Taufiq, R, Sistem Informasi Management, Yogyakarta: Graha Ilmu, 2013, p.18.

[4] Mulyani, S. Metode Analisis dan Peracangan Sistem. Jakarta: Abdi Sistematika.

[5] Pujawan, I., \& Mahendrawathi. (2012). Supply Chain Management, Edisi Kedua. Surabaya: Guna Widya. 